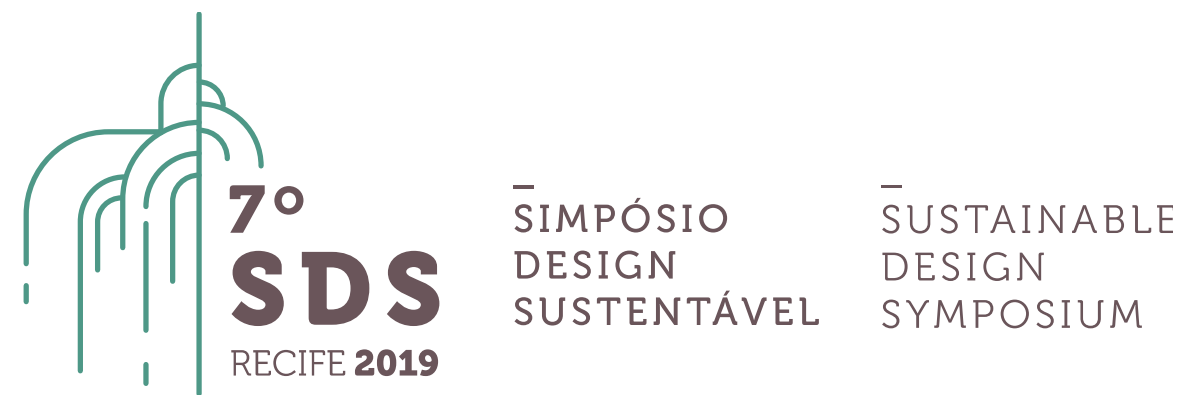

\title{
Indústria da moda e suas relações com a sociedade de risco
}

\author{
Palloma Rodrigues G. Santos ${ }^{1}$, Dra Shirley Gomes Queiroz ${ }^{2}$ \\ 1 Universidade de Brasília, Departamento de Design, Campus Universitário Darcy Ribeiro \\ Instituto Central de Ciências - Ala Norte \\ 2 Universidade de Brasília, Departamento de Design, Campus Universitário Darcy Ribeiro
}

\begin{abstract}
Instituto Central de Ciências - Ala Norte Resumo. O presente artigo faz uma reflexão teórica acerca das mudanças na indústria da moda, e para isso traz uma contextualização histórica do sistema da moda e suas relações com a sociedade e as tecnologias de informação e comunicação de suas respectivas épocas, fazendo uma análise do desenvolvimento até o atual modo de produção. Para analisar as transformações que estão em vigor na contemporaneidade traremos o movimento social global Fashion Revolution como uma forma de reação à dinâmica de produção dos últimos 30 anos ocorridos na indústria da moda, conhecida como fast fashion. O Fashion Revolution faz uso de novas tecnologias de informação e comunicação para um alcance global na disseminação de informações sobre os processos de produção da indústria da moda. Além de informar os consumidores, o movimento busca cobrar das marcas mais transparência sobre seus processos de produção, e nesse sentido, reflete o conceito de sociedade de risco e subpolítica de Ulrick Beck (2002), demonstrando ser uma ferramenta importante para a mudança social neste setor.
\end{abstract}

Palavras-chave. fast fashion, fashion revolution, sociedade de risco, subpolítica

\section{Introdução}

Durante pesquisas acerca do processo de produção do fast fashion ${ }^{a}$, foi observado que existem diversos estudos a respeito do modo de produção do ponto de vista econômico, do modelo de negócio, como estratégia para conquistar mercados globais. Também percebeu-se uma abordagem em relação aos aspectos do comportamento do consumidor e até mesmo questões de sustentabilidade que surgem com esse modelo, no entanto pouco se discute sobre o processo social que consolidou esse sistema e as reações que surgem como resposta a esse modelo devido às transformações sociais que novas tecnologias da informação e comunicação possibilitam.

A moda permeia a sociedade Ocidental Moderna e através dos seus símbolos e signos pode

\footnotetext{
${ }^{a}$ Modo de produção e distribuição de moda de forma muito rápida
} 
nos ajudar a entender as transformações sociais, históricas e econômicas de uma época. Nesse artigo, a indústria da moda é usada como ferramenta para descrever as transformações sociais vividas em nossos tempos, a partir de uma análise bibliográfica e documental. Será necessário fazer uma contextualização histórica a respeito dos sistemas de produção de moda, desde o seu surgimento em meados do século XIV, até a atualidade, para compreender como dinâmicas diferentes transformaram os processos de produção. Essas dinâmicas aqui são entendidas tanto como a forma de pensamento de uma época e movimentos sociais que surgem com ela, tanto as transformações dos meios de informação e comunicação que aceleram as interações.

Entender esse contexto é importante para a compreensão do desenvolvimento da modernidade e a aproximação ao conceito de "modernidade reflexiva" de sociólogos como Anthony Giddens, Ulrich Beck e Scott Lash (1997), para então chegarmos ao debate central do artigo: o modo de produção do fast fashion do ponto de vista da sociedade de risco e a reação a esse modo de produção dentro da modernidade reflexiva, utilizando-se do conceito de subpolítica do sociólogo Ulrich Beck (2002). Esse artigo se propõe a uma reflexão teórica sobre as mudanças contemporâneas da sociedade e como as novas tecnologias da informação e comunicação podem auxiliar nesse processo.

\section{A moda como sistema}

A moda como a conhecemos desenvolve-se em meio a processos históricos do final da Idade Média, no século XIV, e continuam até chegar ao século XIX. O fenômeno moda cria características próprias, sistematizando seus processos e então tomando força no que o autor Hobsbawm (2015) denomina de dupla revolução, caracterizada pela Revolução Francesa e a Revolução Industrial Inglesa, portanto, a partir desse contexto histórico que é possível começar a investigar a natureza humana e os fenômenos socioculturais e suas relações com a moda moderna.

A indústria da moda foi uma das áreas beneficiadas com a revolução industrial, possibilitando a aceleração na fabricação de tecidos e oferecendo maior variedade de itens que antes não eram possíveis com a produção manual, passa-se de uma manufatura para o sistema fabril. A riqueza desloca-se da atividade comercial para a industrial e altera o sistema de poder econômico. A revolução industrial teve como principal fonte de energia o carvão, e a indústria têxtil se desenvolveu através da criação de máquinas de fiar e do tear mecânico, em grande parte se utilizando dessa tecnologia para substituir respectivamente a roca e o tear manual, essas mudanças favoreceram a produção em massa do vestuário (FRIEDEN, 2008).

Historicamente, a grande primeira fase que caracterizou o sistema de produção e difusão da moda como a conhecemos, é definida por Lipovetsky (2009, p. 79) como a "moda de cem anos", e instaurou-se na segunda metade do século XIX. Nesse período surge tanto a Confecção Industrial como a Alta Costura, dois principais sistemas de moda que vão pautar a produção de moda até a contemporaneidade.

A Confecção Industrial se posiciona como uma forma de produção em massa que imita os modelos da Alta Costura, mas com uma qualidade menor ( Lipovetsky, 2009). Ainda em relação à Confecção Industrial, Boucher (2010, p. 355) compartilha dessa percepção quando diz que a "supremacia industrial da Inglaterra triunfa no vestuário pelo custo barato das matérias-primas" sendo essa de baixa qualidade e pouca diferenciação. A Confecção Industrial antecede o que hoje se conhece como Alta Costura, mas seu modo de criação torna-se "monótono", sem grande expressão, e nas palavras de Sennet $(2014$, parte 3 , seção $8, \S 1$ ) "o que viam eram pessoas 
vestidas com roupas cada vez mais homogêneas e monocromáticas". É importante notar como a disseminação da mídia impressa influenciou esse processo, Sennet exemplifica como isso aconteceu:

\begin{abstract}
Cem anos antes, havia duas maneiras de expandir uma moda parisiense: na cidade, a mais efetiva era o contato direto nas ruas ou nos jardins públicos; e os manequins-bonecas que se vestiam como réplicas exatas do que a condessa fulana de tal estava usando no momento. Por volta de 1857, tudo isso havia mudado. Através das "pranchas de elegância", as páginas dos jornais disseminavam a moda de maneira instantânea, e a moda reproduzida em sua forma original exata. Os anos 1840 foram a primeira grande era da circulação maciça de jornais. A simples circulação dos jornais já significava que a maioria dos compradores não precisava mais fazer contato com um vendedor, pessoalmente, com o fito de saber o que comprar. (SENNET, 2014, parte 3, seção 8, §5)
\end{abstract}

O impacto dessas transformações na produção de roupas em Paris e em Londres não pode ser entendido isoladamente dos novos meios de disseminação da moda nas cidades. Esse fator contribuiu para um aumento da informação do consumidor padrão. Enquanto isso, o sistema da Alta Costura, começa a se desenvolver quase que sincronicamente. Sua lógica de produção vai definir o costureiro como artista, assinando a produção com seu nome. Há também a divisão sazonal das peças em primavera-verão e outono-inverno. As principais características desse sistema de produção e difusão foram estabelecidas por Charles Frederic Worth (LIPOVETSKY, 2009) que criou uma organização para o processo de criação e divulgação da moda. Entre elas são destacados:

[...] modelos inéditos, preparados com antecedência e mudados frequentemente, são apresentados em salões luxuosos aos clientes e executados após escolha, em suas medidas [...] os modelos, com efeito, são usados e apresentados por mulheres jovens, os futuros manequins, denominados na época "sósias". Sob a iniciativa de Worth, a moda chega à era moderna; tornou-se uma empresa de criação, mas também de espetáculo publicitário. (LIPOVETSKY, 2009, p.79)

Desde que Worth quebrou as barreiras anteriores da forma de produção do vestuário, criando novas perspectivas para a moda, a Alta Costura passou a nortear, inovar e ditar tendências e encabeçou a maneira de se produzir moda, sendo seguida e imitada por todos os setores da indústria da moda, essa lógica se manteve até a década de 1960, a partir dessa época vivenciamos o que Lipovetsky (2009, p. 123) chamou de "moda aberta", sendo essa considerada por ele a segunda fase da moda moderna.

\title{
2.1 Década de 1960, os jovens e o ready-to-wear
}

A década de 1960 foi uma época de grandes transformações sociais. Boucher (2010) afirma que esse período apresentou uma alta taxa de natalidade dos anos de 1945 a 1965, possibilitando uma massa jovem jamais conhecida, que originou uma nova denominação: a juventude. Segundo Vianna (1992, p.2) "a juventude é então uma categoria etária que foi incorporada pela cultura de massa a partir do mito da "juventude rebelde/revolucionária".

5 a $10 \%$ da população mundial têm menos de vinte anos - aparece dispondo de recursos financeiros superiores, no conjunto, ao de seus pais na mesma idade. [...]. Pela primeira 
vez, "os jovens", como se começa a chamá-los com uma ponta de apreensão, são considerados uma categoria à parte, com ocupações, gostos e modos de vestir específicos.

(BOUCHER, 2010, p. 413)

Caracterizado por acontecimentos como o surgimento do movimento jovem, a busca da emancipação feminina e a rejeição da divisão de classes, esse período criou e difundiu diferentes modas ao mesmo tempo, possibilitando uma expansão do mercado de moda, incorporando os movimentos jovens ao seu sistema (AVELAR, 2011). As transformações tecnológicas, principalmente na comunicação, o uso de novas tecnologias de massa tiveram grande impacto na formação da sociedade da época, revistas abundantemente ilustradas com fotografias coloridas, cinema e televisão foram ferramentas fundamentais para a difusão da informação de moda (BOUCHER, 2010), dessa maneira, a moda deixa de ser um domínio apenas da alta classe.

Na moda aberta pela primeira vez é o comércio quem comanda a lógica de produção de moda, e é possível perceber uma produção serial, coleções sazonais com novos focos e critérios de criação baseados em lógicas de consumo produzidas em decorrência dos grupos jovens (ERNER, 2015). Crane (2011, p. 20) afirma que a moda do consumidor passou a oferecer "muito mais diversidade estilística e muito menos consenso a respeito do que estava na moda", esse modo de pensamento possibilitou o desenvolvimento da "identidade social" (CRANE, 2006), os grupos jovens não se preocupavam em parecer de um determinado status social, o que importava era o "estilo".

A Alta Costura então perde seu posto de única inovadora, a moda começa a surgir de fontes diversas, principalmente das ruas, Crane (2011, p.186) ressalta que a moda "tornou-se um meio de expressão das nuances de individualidade baseado na percepção de gênero, orientação sexual, idade, raça e etnia". Boucher (2010, p. 414) relata que "a fabricação em série é a única capaz de fornecer roupas de todos os tipos a um preço módico", e de fato, graças aos diversos estilos que surgem com a ascensão jovem, e a busca incessante pela identidade, é possível o surgimento da fabricação industrial chamada ready-to-wear em inglês, ou prêt-à-porter em francês, que significa "pronto para usar". "A moda nunca fora concebida senão para adultos" (BOUCHER, 2010, p. 413), e por isso a chegada dos anos 1960 foi tão impactante na indústria da moda, ser jovem torna-se uma qualidade.

A televisão, o cinema e a música foram ferramentas importantes para a divulgação da cultura jovem nos anos 1960, assim como os jornais foram importantes e transformaram a forma de consumir em meados de 1800 . Crane (2011, p.187) pontua que "as redes sociais urbanas [...] foram muito eficientes para a circulação de informações sobre moda", mas ressalta que atualmente "o mundo eletrônico da moda" é quem compete com o antigo sistema, sendo que seu exemplo foca na mídia musical, mas a televisão e o cinema, principalmente por trabalharem com imagem, também são grandes responsáveis pela disseminação da cultura jovem. Em decorrência dessas mudanças, ao longo dos anos 1960 e final do século XX, surgiram estilos denominados subcultura ou antimoda, como os hippies e os punks, por exemplo, que representaram um anticonformismo exacerbado (LIPOVETSKY, 2009), são diferenças que agora passam a ser incorporadas ao sistema da moda (AVELAR, 2011)

Apesar dessas mudanças, a Alta Costura soube se adaptar a situação e passou a se apropriar das subculturas/antimodas como fonte de inspiração e criação, portanto, apesar das mudanças, a Alta Costura manteve seu posto de prestígio, mas não era mais a única referência do processo de criação, agora, o ready-to-wear ganhava cada vez mais espaço, possibilitando o crescimento e expansão de um novo mercado. 


\title{
2.2 Globalização e o surgimento do fast fashion
}

Atualmente, o sistema da moda vive um período o qual Lipovestsky (2009, p. 184) chama de "moda consumada", que é caracterizada não só pela indústria da moda, mas por todas as indústrias que se apropriaram da lógica de produção da moda como ferramenta para o mercado moderno, transformando a produção e o consumo de massa sob a lei da obsolescência, sedução e diversificação. Até os anos 1980, a prática industrial tinha um foco local, mas com a globalização, surge um novo conceito de produção, a produção flexível em oposição ao modelo de produção fordista. Enquanto a produção fordista centraliza o modo de produção, a produção flexível tem como principal característica a descentralização da produção (KUMAR, 1997). A produção flexível, aliada à globalização, tem cada vez mais setores buscando segmentar e adaptar seus produtos para atender à demanda por diferenciação (Cardoso, 2016), com isso surgem novas lógicas de trabalho, onde grandes empresas se aliam a pequenas empresas no mundo todo para a produção de diversos produtos, Kumar (1997) exemplifica esse modo de produção usando a empresa italiana Benetton ${ }^{\mathrm{b}}$.

\begin{abstract}
Um Bom exemplo é a Benetton, muito bem-sucedida empresa italiana produtora de roupas. [...] As principais instalações próprias da Benetton - que empregam cerca de 1500 trabalhadores - são complementadas por uma rede de mais de 200 subcontratantes pequenas empresas com 30 a 50 empregados cada, e que no total empregam cerca de 10.000 pessoas. Essas empresas contribuem - com algum custo para elas mesmas - para flexibilidade adicional do volume. Afirmam os especialistas que, graças a esse sistema integrado de produção flexível, a Benetton reduziu o tempo de resposta à mudança no mercado para apenas dez dias séries [...] Não há dúvida de que a Benetton é famosa em todo o mundo por se antecipar às tendências da moda e adaptar a produção exatamente aos estilos em mutação de diferentes subculturas e grupos etários. (KUMAR, 1997, p. 57)
\end{abstract}

A moda consumada representa características sociais moldadas a partir do desenvolvimento tecnológico, da difusão do uso da internet, dos meios de comunicação online, da variedade e da abundância de ofertas de produtos, e junto da produção flexível possibilitou, no sistema da moda, o surgimento do que hoje conhecemos como fast fashion, que visa atualização constante no menor tempo-espaço, ou seja, maior variedade de produtos em menos tempo e em grande escala, distribuídos globalmente. Crane (2011, p. 267) afirma que quando a indústria da moda se globalizou, as tendências da moda tornaram-se mais numerosas e ficou mais difícil prever os gostos dos consumidores, por esse motivo surgem as fast fashion, que atendem essa necessidade de rápida transformação.

A adoção do fast fashion é o resultado de um processo que reduziu o intervalo de tempo entre a criação e o consumo, a ascensão da internet e dos meios de comunicação digital tiveram grande influência na consolidação da forma de produção do fast fashion. Gama (2012, p. 9) exemplifica esse processo do uso das mídias digitais com a rede varejista Zara, que "passaram a estar conectadas com as inovações através da Web, das redes sociais, onde os desfiles são cada vez mais difundidos em tempo real", e que possibilita a replicação dos produtos, antes mesmo que as marcas desfiladas distribuam a produção para as lojas. Assim como as mídias de meados de 1800 e 1960 influenciaram os modos de difusão da informação, as novas tecnologias de informação e comunicação (NTIC's) aliadas à internet agora tem um grande impacto para o

\footnotetext{
${ }^{\mathrm{b}}$ Segundo Integrated Report de 2017, a empresa possui atualmente 5.113 lojas e 7.505 empregados. Disponível na página da empresa, ver referências.
} 
crescimento de novas formas de consumo. O acesso à informação possibilita a sociedade a escolher, dentro de uma gama de alternativas, quais estilos elas vão adotar como identidade. A partir dessa perspectiva, Crane (2011, p. 192) afirma que "a moda industrial é uma forma de cultura de mídia, no sentido de que seus valores e atrativos para o consumidor são amplamente criados pela publicidade" e através do uso de NTIC's, são imensamente difundidos através das plataformas digitais.

Se por um lado as empresas de fast fashion oferecem variedade de produtos a preços razoáveis para um público que até então não conseguia consumir moda, sendo nomeado constantemente pela imprensa de "democratização da moda", por outro lado as roupas ganharam um valor de descartável, por conta da má qualidade da matéria prima e da finalização dos produtos devido à aceleração da produção. Não apenas isso, a forma de produção flexível utilizada pelas grandes cadeias varejistas no início dos anos 1980 trouxeram problemas sociais para os trabalhadores de países subdesenvolvidos, como por exemplo, a mão de obra análoga ao de escravo, condições precárias de trabalho, salários baixíssimos, entre outras questões, além dos problemas ambientais relacionados ao modo de produção acelerado e alta taxa de poluição. Se antes o sistema da moda era pautado por duas coleções ao ano, atualmente as grandes redes de fast fashion oferecem uma nova coleção a cada duas semanas (GAMA, 2012).

Aparentemente, Kumar (1997) fala com otimismo da forma de produção flexível, não prevendo os riscos que isso poderia causar. Ao exemplo da mesma empresa citada pelo autor, a Benetton, que era uma das empresas que trabalhava com a fábrica Rana Plaza, em Bangladesh, e que em 2013 por más condições da estrutura do prédio, ruiu, matando mais de 1.100 trabalhadores. ${ }^{c}$ Esse dia foi um marco para indústria da moda, pois mostrou a verdadeira face do modo de produção flexível, ganhando a mídia e abrindo portas para discutir as questões éticas dentro da indústria da moda. É importante perceber que apesar do fast fashion ser o grande beneficiado desse sistema de produção, marcas de ready-to-wear e da Alta Costura, também estão se utilizando dessas ferramentas para melhorar seu desempenho econômico, ignorando completamente as questões sociais e ambientes. Essa postura levou alguns profissionais, estudantes, trabalhadores e pesquisadores da área a se questionarem a respeito desse modo de produção e se mobilizarem contra esse sistema.

\section{Modernidade Reflexiva e Mídias online}

Com o avanço da sociedade industrial, surgem novos modos de produção e o desenvolvimento de novas tecnologias. Como visto anteriormente, as formas de difusão da informação e novos meios de comunicação, influenciam a sociedade e seus comportamentos. Desde os anos 1980, novas tecnologias de informação e comunicação têm possibilitado transformações na forma de pensar, Beck, Giddens e Lash (1997) nomearam esse novo modelo que surge de modernidade reflexiva. Essa teoria crítica representa uma possibilidade de reinvenção da modernidade e de suas formas industriais, portanto, a modernidade reflexiva, aparece em oposição à modernidade industrial em que vivemos, constituindo um dos principais mecanismos dessa "reflexividade" a "autodestruição" de um modelo obsoleto, sendo o Fashion Revolution um bom exemplo para ilustrar esse conceito que será abordado logo à frente.

A expressão modernidade reflexiva abrange as transformações contemporâneas, que envolvem a individualização e a ruptura com o tradicional, essas características são intrínsecas ao

\footnotetext{
${ }^{\mathrm{c}}$ Matéria publicada no site Business of Fashion adaptada, tradução nossa.
} 
sistema da moda desde sua aparição na idade média, e se estabelecem com ainda mais força na atualidade, proporcionada principalmente pelo advento da internet. Hall (2006, p. 75) também observa essas transformações e afirma que "quanto mais à vida social se torna mediada pelo mercado global de estilos [...], pelas imagens da mídia e pelos sistemas de comunicação globalmente interligados, mais as identidades se tornam desvinculadas". Com essa perspectiva, origina-se a ideia de crise defendida por Beck (2002), no sentido de imprevisibilidade e incerteza de quase tudo o que nos cerca. Beck, Giddens e Lash (1997) afirmam que a "modernização reflexiva" representa a "(auto) destruição criativa" da sociedade industrial. É possível notar essa (auto) destruição criativa nas novas formas de produção da moda e de consumo da moda, onde velhos paradigmas são questionados, como por exemplo, questões de gênero das roupas:

[...] a sociedade moderna está acabando com suas formações de classe, camadas sociais, ocupação, papéis dos sexos, família nuclear, agricultura, setores empresariais e, é claro, também com os pré-requisitos e as formas contínuas do progresso técnico-econômico. (BECK, GIDDENS, LASH, 1997, p.12)

Beck, Giddens e Lash (1997, p. 13), em Modernização Reflexiva afirmam que "não é a crise [...] mas as vitórias do capitalismo que produzem a nova forma social", a partir dessa perspectiva podemos afirmar que a consolidação do fast fashion, e consequentemente os problemas advindos dessa forma de produção, levou a sociedade a questionar os métodos utilizados por esse sistema. Essa visão da modernidade reflexiva aliada a "era da informação", que se utiliza das novas tecnologias de informação e comunicação como fonte inesgotável de acesso e difusão da informação, e cria novas dinâmicas na sociedade, atuam de modo mais "horizontal" como afirma Castells (2011), já que o consumidor não é mais considerado um agente passivo e tem voz em plataformas digitais. Ainda nessa percepção Castells diz:

A passagem dos meios de comunicação de massa tradicionais para um sistema de redes horizontais de comunicação organizadas em torno da internet e da comunicação sem fio introduziu uma multiplicidade de padrões de comunicação na base de uma transformação cultural fundamental à medida que a virtualidade se torna uma dimensão essencial da nossa realidade. (CASTELLS 2011, p. I-II)

Os meios de comunicação digitais, através do uso da internet, não apenas possibilitou a aceleração ao acesso a informação de moda, como também ao crescimento do comércio online, ou seja, eles ampliam ou aceleram os processos já existentes, processos esses que chancelam o modo de produção fast fashion, principalmente pelo alcance global, em números de pessoas, que têm acesso a esse tipo de ferramenta. Certamente, os meios de comunicação digitais também possibilitaram que marcas menores tivessem visibilidade, dando crescimento a um mercado que foi chamado por Anderson (2006) de cauda longa, tendo como fator principal a tecnologia como conversora do mercado de massa em mercado de nicho.

O surgimento do conceito de mercado de nicho possibilita, além da emancipação de pequenos produtores para a divulgação de seus produtos em plataformas online, concorrendo com grandes empresas, como também a reação ao modo de produção fast fashion. Conceitos como o minimalismo, princípio que reduz ao mínimo o emprego de elementos ou recursos, armário cápsula, um guarda-roupa com um número menor de peças que combinem entre si reduzindo o consumo de peças desnecessárias, slow fashion, um movimento sustentável, que se opõe ao fast fashion e tem como princípio a produção mais lenta, entre outros, podem divulgar suas ideias através do uso das NTIC's. 
Apesar de esses conceitos terem alguns pontos a serem questionados, tanto nas suas práticas como nos princípios, eles não deixam de ser um importante retrato dos acontecimentos na nossa sociedade, e acabam ganhando força por conta da forma descentralizada que é o ambiente digital. A internet também pode ser usada como ferramenta para difusão da informação a respeito de processos mais conscientes no consumo de moda. Apesar desses conceitos de consumo citados anteriormente terem sua relevância, o movimento que tem ganhado força é o Fashion Revolution. O Fashion Revolution é um movimento global, que surgiu após a queda do prédio da fábrica Rana Plaza em 2013, eles se auto descrevem como:

Nós somos a Revolução da Moda. Somos designers, produtores, fabricantes, trabalhadores e consumidores. Somos acadêmicos, escritores, líderes empresariais, marcas, varejistas, sindicatos e formuladores de políticas. Nós somos a indústria e o público. Nós somos cidadãos do mundo. Somos um movimento e uma comunidade. Nós somos Você. Nós amamos moda. Mas não queremos que nossas roupas explorem pessoas ou destruam nosso planeta. Nós exigimos mudanças radicais e revolucionárias. ( FASHION REVOLUTION, [s.d], p.1, tradução nossa)

Esse movimento surgiu com o objetivo de fazer com que as pessoas tenham consciência sobre a origem e os processos de produção das roupas que elas consomem, e cobrar das marcas mais transparência a respeito dos seus processos de produção. As plataformas online de comunicação chamadas de "redes sociais" tem um papel muito importante nesse movimento, pois os discursos tomam força conforme a informação é difundida, com o crescimento da rede e o fortalecimento da comunidade. Essa nova forma de pensar deve-se principalmente pelo processo da modernidade reflexiva a que se refere Beck, Guiddens e Lash (1997).

\subsection{Sociedade de risco e subpolítica na moda}

Para entender a atualidade e como chegamos até esse movimento do Fashion Revolution, é importante compreender o que é a sociedade de risco e o surgimento da subpolítica. Dentro do pensamento da modernidade reflexiva, Beck (2002, p.237) argumenta que sociedade de risco "se caracteriza essencialmente por uma carência: a impossibilidade de prever exatamente as situações de perigo", portanto a sociedade de risco é orientada pelos problemas que podem surgir a partir das transformações da sociedade industrial, e por consequência trazer situações de risco para a humanidade, nesse sentido, a situação de risco não é uma coisa externa, mas sim um problema em que a origem vem do próprio homem (BECK, 2002). Assim, a "globalização dos riscos" revela a dificuldade que as instituições têm de prever, organizar e controlar o risco num mundo de redes globais interativas.

Beck (2002, p. 237) diz que "o risco se converteu em motor da autopolitização da sociedade industrial", por esse motivo o autor traz o conceito de política e de subpolítica dentro da modernidade reflexiva. A política é definida por ele como "a participação do cidadão nas instituições de democracia política (partidos, parlamentos, etc)" (BECK, 2002, p. 238), já a subpolítica significa "moldar a sociedade de baixo para cima" (BECK, GIDDENS, LASH, 1997, p.35), ou seja, agentes externos ao conceito de política se organizam reivindicando pautas de seus interesses. Beck (1997, p.50) também compara os dois sistemas e diz que "a distinção entre a política oficial e a subpolítica é a distinção entre política "simples", dirigida por regras, e política reflexiva, que altera as regras". De acordo com essa definição podemos classificar o movimento Fashion Revolution como um ato de subpolítica. 
O Fashion Revolution representa os anseios de uma sociedade de risco que se preocupa com os problemas oriundos do modo de produção industrial. Esse movimento une pessoas no mundo inteiro para melhorar um problema que existe na sociedade, mas não tem sido combatido pelas instituições e governos responsáveis. Pessoas, em geral profissionais ou simpatizantes da moda, se organizam para cobrar das empresas atitudes mais transparentes já que o governo não toma medidas severas em relação a esses problemas. Apesar de acontecer um encontro presencial anualmente, desde 2013 , no dia do desabamento do prédio Rana Plaza (24 de abril), ao mesmo tempo no mundo todo, com ciclos de palestras e oficinas, a forma "mais ativa" que o movimento encontrou para fazer pressão na indústria foi divulgando informação, utilizando-se das novas tecnologias de informação e comunicação online, utilizando-se das redes sociais como principal plataforma.

O que torna o movimento interessante são dois pontos principais, o primeiro: ele antes de tudo é um movimento online, e segundo ele é o primeiro movimento global que acontece simultaneamente no mundo todo ao mesmo tempo, e conserva os mesmos princípios e valores. $O$ movimento conseguiu atingir um público que não sabia como a indústria da moda funcionava. A plataforma mostra o impacto da divulgação das informações sobre a indústria da moda, no mundo inteiro anualmente. Os relatórios ficam disponíveis no site e tem acesso livre. Em certa medida, a indústria respondeu a essas manifestações, podemos encontrar um relato no próprio site do Fashion Revolution (2017):

\footnotetext{
"Marcas globais como Zara, Fat Face, Massimo Dutti, Pull and Bear, G Star Raw, Marks and Spencer, Marimekko e Gildan estão entre as mais de 2000 marcas e revendedoras de moda que responderam com informações reais sobre seus fornecedores ou fotos de seus trabalhadores dizendo \#eufizsuasroupas, quase o dobro do número que respondeu no ano passado." (FASHION REVOLUTION BRASIL, 2017, pag. 5)
}

O movimento completou cinco anos em 2018, e a cada ano o número de países que aderem ao movimento aumenta, o número de alcance nas redes sociais também cresce junto. Apesar de ser um fenômeno novo, podemos afirmar que esse movimento tem sido influente na indústria da moda, já que empresas tiveram que repensar práticas e se adaptar diante dos relatos e das críticas divulgadas nas novas mídias digitais. Por mais que o consumo tenha sido considerado por muito tempo como uma "atividade privada e apolítica" (CRANE, 2011, p. 232), na modernidade reflexiva ele pode se tornar uma forma de subpolítica e ter um impacto na cultura e na sociedade como um todo.

\section{Considerações finais}

Na lógica da produção de massa, o valor de troca se sobressai ao valor de uso, ou seja, a perspectiva de mercado ultrapassa a perspectiva afetiva, e esse discurso se perpetua de maneira eficiente. No entanto, alguns movimentos online trazem novas questões à tona, o discurso do ser ao invés de parecer ganha força. Segundo Vianna (1992, p.4) "estamos condenados ao simulacro produzido enquanto projeto, processo e mercadoria controlada pelos detentores dos meios de (re) produção técnica (ou indústria cultural)", mas se a lógica de produção não parte mais apenas das grandes empresas, com o uso da internet seria possível essa mudança?

Atualmente, a sociedade passa por um momento de reflexividade, ou seja, que se volta sobre si mesma e questiona práticas e processos, onde seus atos geram riscos, e causam 
"exaustão, desintegração e desencantamento" (BECK, GIDDENS, LASH, 1997, p. 18). Nesse processo de reflexividade, surgem movimentos, como o Fashion Revolution, que questionam os problemas que a indústria da moda traz para a sociedade, esse movimento além de representar as questões de uma sociedade de risco, mostra que o ato de subpolítica, atualmente faz parte da nossa sociedade, e aliada a novas tecnologias de informação e comunicação pode causar impacto na indústria, e alterar a dinâmica da produção que se apresenta desde os anos 1980 na indústria da moda. Portanto, podemos afirmar que movimentos como o Fashion Revolution são uma importante inovação social para a indústria da moda.

Pensar a moda a partir do surgimento de movimentos éticos, conforme aponta Fletcher e Grose (2011), implica utilizar novos processos, novos paradigmas, novas soluções que levem em conta a demanda contemporânea de consumo, que é pautado no protagonismo. Pode também traduzir-se numa inovação consciente e não apenas na produção do produto. Dessa forma, seria possível pensar numa cadeia de produção que avalie o processo de maneira sistêmica, desde sua criação até o pós-uso, priorizando assuntos relacionados a questões socioambientais. Cardoso (2016) afirma que:

O olhar é também sujeito a transformações no tempo, e aquilo que depreendemos do objeto visto é necessariamente condicionado pelas premissas de quem enxerga e de como se dá a situação do ato de ver [...] o olhar é uma construção social e cultural, circunscrita pela especificidade histórica do seu contexto. (CARDOSO, 2016, p. 37)

Nesse sentido podemos dizer que as mídias sociais possibilitaram que grupos de diferentes lugares do mundo se organizassem de acordo com seus gostos, interesses (CASTELLS, 2017). E dessa junção surgem novas formas de percepção do mundo de enxergar os objetos produzidos. Além disso, a sociedade em rede online possibilitou novas formas de pensar, consumir, produzir e se organizar. Nesse contexto, as mídias sociais permitiram que surgisse, entre tantas novas manifestações, o movimento Fashion Revolution. Podemos afirmar que os movimentos sociais online como o Fashion Revolution, são extremamente relevantes para o processo de mudanças de percepção sobre os produtos de moda e talvez, também para a cultura do consumo. Castells (2017) acredita que o uso das redes sociais é uma importante ferramenta de transformação social, ele afirma que:

[...] a única questão relevante para se avaliar o significado de um movimento social é a produtividade histórica e social de sua prática e seu efeito sobre os participantes como pessoas e sobre a sociedade que ele tentou transformar. Nesse sentido, é muito cedo para avaliar o resultado final desses movimentos, embora já possamos dizer que regimes mudaram, instituições foram desafiadas e a crença no capitalismo financeiro global triunfante foi abalada [...] o legado de um movimento social consiste na mudança cultural que produziu com sua ação. (CASTELLS, 2017, p.266)

Cardoso (2016, p.35) observa que "quando se compreende a lógica segundo a qual as formas são constituídas, compreende-se também que elas são passíveis de mudança e de adquirirem novos significados". Podemos considerar que, os movimentos sobre conscientização a respeito dos processos de produção da indústria da moda, tem tido impacto em transformações sociais, ainda que de forma lenta. Mas certamente veem contribuindo para uma nova percepção em relação às práticas de consumo, e aos processos que envolvem a fabricação dos bens materiais e talvez, estes venham a ter novos formatos e novos significados. 


\section{Referências}

ANDERSON, Chris. A cauda longa. Elsevier Brasil, 2006.

AVELAR, Suzanna. Moda, globalização e novas tecnologias. Estação das Letras e Cores; Rio de Janeiro, 2011.

BECK, Ulrich. La sociedad del riesgo global. Paidós Básica, 2002.

BECK, Ulrich; GIDDENS, Anthony; LASH, Scott. Modernização reflexiva: política, tradição e estética na ordem social moderna. Unesp, 1997

BOUCHER, François. História do vestuário no Ocidente. São Paulo: Cosac Naify, 2010.

CARDOSO, Rafael. Design para um mundo complexo. São Paulo: Cosac Naify, 2016.

CASTELLS, Manuel. A sociedade em rede, vol. 1. São Paulo: Paz e Terra, 1999.

. Redes de indignação e esperança: movimentos sociais na era da internet. Zahar, 2017.

CRANE, Diana. A moda e seu papel social: classe, gênero e identidade das roupas. Editora Senac São Paulo, 2006.

_.. Ensaios sobre moda, arte e globalização cultural. São Paulo: Editora Senac, 2011.

ERNER, Guillaume. Sociologia das tendências, 1a ed. São Paulo: Gustavo Gili, 2015

FLETCHER, Kate; GROSE, Lynda. Moda \& Sustentabilidade: design para mudança. São Paulo: Senac, 2011.

FRIEDEN, Jeffry A. Capitalismo global: história econômica e política do século XX. Rio de Janeiro: Zahar, 2008

GAMA, Maria Gabriela, ZARA: um case study à escala global : http://hdl.handle.net/1822/29573

HALL, Stuart. A identidade cultural na pós-modernidade.Rio de Janeiro: DP\&A, 2006.

HOBSBAWM, Eric. A era das revoluções: 1789-1848. Editora Paz e Terra, 2015.

KUMAR, Krishan. Da sociedade pós-industrial à pós-moderna: novas teorias sobre o mundo contemporâneo. Zahar, 1997.

LIPOVETSKY, Gilles. O império do efêmero: a moda e seu destino nas sociedades modernas. São Paulo: Companhia das Letras, 2009.

SENNETT, Richard. $O$ declínio do homem público: as tiranias da intimidade. [recurso eletrônico] 1. ed. Rio de Janeiro : Record, 2014.

VIANNA, Letícia CR. A idade mídia: uma reflexão sobre o mito da juventude na cultura de massa. Universidade de Brasília, Instituto de Ciências Humanas, Departamento de Antropologia, 1992.

Links:

Business of Fashion. Preventing Another Rana Plaza. 16 de setembro de 2013 . Disponível em: $<$ https://www.businessoffashion.com/articles/opinion/op-ed-preventing-another-rana-plaza> Acesso em: 14/07/2017

Fashion Revolution Week 2017. Disponível em: <https://www.fashionrevolution.org/brazil- 
blog/fashion-revolution-week-2017-portuguese/ >. Acesso em: 23/05/2018

Integrated Report 2017. Disponível em: <http://assets.benettongroup.com/wpcontent/uploads/2018/06/Integrated_Report_1_video.pdf > . Acesso em: 25/08/2018

Manifesto for a Fashion Revolution. Disponível em:

<https://www.fashionrevolution.org/manifesto/> Acesso em: 20/06/2018 